\title{
Social-ethical issues concerning the control strategy of animal diseases in the European Union: A survey
}

\author{
Nina E. Cohen, ${ }^{1}$ Marcel A.P.M. van Asseldonk ${ }^{2}$ and Elsbeth N. Stassen ${ }^{1}$ \\ ${ }^{1}$ Wageningen Institute for Animal Sciences, Animal Production Systems Group, Animals and Society, Wageningen University, \\ Wageningen, The Netherlands; ${ }^{2}$ Business Economics Group, Wageningen University, Wageningen, The Netherlands
}

Accepted in revised form November 9, 2007

\begin{abstract}
In 2004 a survey was conducted in the member states of the European Union designed to gain greater insight into the views on control strategies for foot and mouth disease, classical swine fever, and avian influenza with respect to the epidemiological, economic and social-ethical consequences of each of these animal diseases. This article presents the results of the social-ethical survey. A selection of stakeholders from each member state was asked to prioritize issues for the prevention and control of these diseases. A majority of stakeholders chose preventive measures as the preferred issue. An analysis was done to determine whether there were differences in views expressed by stakeholders from member states with a history of recent epidemics and ones without such a history, and whether there were regional differences. There were no differences between member states with or without a history of recent epidemics. There were indeed regional differences between the priority orders from Northern and Southern Europe on the one hand, and from Eastern Europe on the other.
\end{abstract}

Key words: Animal welfare, Avian influenza, Classical swine fever, Control strategy, Culling of healthy animals, Foot and mouth disease, Preventive measures, Socio-psychological and ethical issues, Vaccination

Nina E. Cohen is a biologist and is a researcher at the Wageningen University. She is specialized in societal and ethical issues in human-animal relationships. Her current research is focused on the social-ethical issues concerning the prevention and control of foot and mouth disease, classical swine fever and avian influenza.

Marcel A.P.M. van Asseldonk has studied animal science. Currently he works at the Institute for Risk Management in Agriculture (IRMA) of the Wageningen University. He is specialized in the design and pricing of insurance policies and animal health funds for the main livestock epidemics.

EIsbeth N. Stassen is a veterinarian and professor of Animals and Society at the Wageningen University. Elsbeth Stassen is specialized in animal health, animal welfare and human-animal relationships. She was a member of a governmental welfare committee during the avian influenza epidemic in the Netherlands in 2003.

\section{Introduction}

The European Union (EU) has recently faced major outbreaks of foot and mouth disease, avian influenza (bird flu), and classical swine fever. The Netherlands recently experienced three major epidemics: classical swine fever in 1997-1998, foot and mouth disease in 2001, and avian influenza in 2003. The United Kingdom suffered a major foot and mouth epidemic in 2001, and Italy was confronted with avian influenza epidemics in 1997-1998 and again in 2000. In 2006 classical swine fever has again been reported in Germany, and avian influenza has been identified in several member states.
In 1992 the European Union adopted a non-vaccination policy. This meant that animals were no longer vaccinated against certain infectious diseases and the control strategy was based on the stamping-out of an epidemic. This involved a standstill (movement restrictions) followed by the culling of all infected and healthy but susceptible animals within a $1-3 \mathrm{~km}$ area from the source(s) of the infection. This non-vaccination policy was considered to have two advantages over preventive vaccination. First, a non-vaccination policy is believed to stimulate free market trade of animal products between countries who have adopted this policy. Second, calculations indicated that the costs of preventive vaccination would be higher than the costs involved with controlling 
an epidemic (Koninklijke Nederlandse Akademie van Wetenschappen, 2002). Accordingly, during each of the recent epidemics in Europe animals were not protected by vaccination, and stamping-out was the strategy of choice. Under this strategy, not only infected animals, but also millions of healthy animals were culled in the efforts to eradicate the diseases. During the foot and mouth disease epidemics more that 4 million animals were culled; during the classical swine fever epidemics more that 13 million animals were culled; and during the avian influenza epidemics more that 41 million animals were culled. ${ }^{1}$ These numbers include not only production animals destined for the food chain, but also backyard animals kept for non-commercial recreational purposes. The European Council Directive which introduced community measures against certain animal diseases does not distinguish between production animals and backyard animals, even though the latter group is not usually destined for food production or export purposes.

This stamping-out strategy has had a devastating impact on society as a whole. It has caused severe trauma to the people involved and has raised many questions about the morality of culling so many healthy animals and about the animal welfare problems resulting from improper handling and slaughtering of animals. The general public was confronted with footage of burning pyres of slaughtered animals and with the anger and grief of traumatized farmers and other animal keepers. In some member states this strengthened the position that adopting alternative strategies for future epidemics was imperative, to better take into account society's changing ethical views on the culling of healthy animals, animal welfare, and the psychological impact on those persons directly involved. This led to an increasing demand to reconsider the European non-vaccination policy and discuss alternative future prevention and control strategies that would be acceptable to and supported by society at large.

\section{Socio-psychological issues}

Several studies have been performed to describe the social and psychological consequences of animal epidemics (van Haaften and Kersten, 2002; Cumbria Foot and Mouth Disease Inquiry Panel, 2002; Institute for Health Research, 2002; Huirne et al. 2002; van Velzen and Dekker, 2003).

After the last foot and mouth epidemic in the United Kingdom in 2001, an inquiry was performed in North Cumbria into the health and social consequences the crisis had on farmers and their families, on workers in related businesses, and on veterinarians and others directly involved (Cumbria Foot and Mouth Disease Inquiry Panel, 2002). The findings of the studies identified several social and psychological issues. The mental health indicators indicated post-traumatic stress symptoms in farmers and in frontline workers involved in the culling and disposal of the animals. These symptoms were caused by stress created by circumstances over which these individuals had little control. Farmers had experienced a loss of confidence in central and local decision-makers and a loss of self-esteem and selfconfidence due to a number of recent agricultural shocks that called their way of life and their social identity into question. Recent crises resulted in a decrease in public confidence in large-scale agricultural production methods. Stress was caused not only by the social isolation, the damage done to the social network, and insufficient communication from and with the authorities. The severe restrictions on animal movement, denying farmers access to their animals, the traumatic on-farm slaughter of healthy animals, and the burning pyres all combined to cause major traumas. On top of the social stress, farmers and affected non-farming businesses such as the tourism sector experienced a loss of work and income. Diversified farms combining farming and bed and breakfast facilities suffered double losses. The conclusion was that the authorities had offered insufficient assistance in business recovery, leaving many farms and businesses faced with debts.

In 2001 van Haaften and Kersten (2002) performed a study among 661 Dutch dairy farmers who had been affected by the 2001 foot and mouth epidemic in the Netherlands to assess the social and psychological impact of the epidemic. The farmers were interviewed about their mental well-being (or lack thereof). The results showed that between $20 \%$ and $30 \%$ of the respondents suffered from socio-psychological problems such as stress, restlessness, tension, anxiety and depression, feeling downhearted and isolated, and sleeping disorders.

In another study, conducted by Huirne et al. (2002), a questionnaire was sent to 662 respondents among the Dutch general public. The results showed that the foot and mouth epidemic left a deep impression, especially with respect to the way the animals had been culled and disposed of $(73 \%)$. Other elements of concern were the emotional and financial impact on the farmers, the way the crisis had been handled by the authorities, the isolation of the farmers, and the fact that animals were no longer seen in the countryside. The preferred strategy during a future outbreak was vaccination of all animals $(70 \%)$ and isolation $(54 \%)$, while a majority $(72 \%)$ dismissed culling healthy animals to stop the spread.

The foot and mouth and the avian influenza epidemic in the Netherlands have led to the mass destruction of not only production animals, but also of many backyard animals, some of which were rare breeds. The control strategy has been the cause of much unrest and protests among the keepers of backyard animals. Most were in favor of vaccination and were not at all convinced of the 
necessity of the culling of their animals based on economic considerations (van Velzen and Dekker, 2003).

\section{Communication}

Insufficient communication with the authorities has contributed to heightened stress and trauma for all involved, and has been described by the Cumbria Foot and Mouth Disease Inquiry Panel (2002) and by van Haaften and Kersten (2002). The latter study describes how prior to the 2001 foot and mouth disease epidemic in the Netherlands, stakeholders were insufficiently prepared for an emergency situation and had not anticipated that a crisis would occur so soon. In the United Kingdom the authorities started planning only after the onset of the epidemic and failed to involve all stakeholders in the decision-making process for a draft contingency plan (such as the tourism sector and nature and environmental organizations). The resulting contingency plan thus operated from a veterinary approach only, without the support from other relevant stakeholders.

During the 2001 epidemic in the Netherlands there was insufficient communication between the Ministry of Agriculture and local authorities. The contingency plan had played a central role in the control strategy, but it was too focused on the veterinary aspects. There had been little cooperation between stakeholders and the Ministry of Agriculture at the national level and stakeholders took no part in the decision-making process, even though their expertise would have been very valuable. The contingency plan failed to anticipate either the importance of a joint strategy or the emotional consequences to those involved. On a positive note, however, cooperation at the regional level was effective.

After the crisis compensation payments were often delayed and were not transparent. By this time many stakeholders had changed their views about the stampingout policy and had turned against the massive culling of so many healthy animals and rare breeds. The policy to allow the import of vaccinated products from Argentina was considered inconsistent. Only then did the Ministry of Agriculture come to realize the importance of an interactive approach with active involvement of all stakeholders and that the contingency plan should include social as well as veterinary aspects.

\section{Animal welfare}

During and after the recent animal disease epidemics, the animal welfare problems encountered were a major topic in the public discussion and remain so to this day. The Farm Animal Welfare Council in its report to the British authorities (Farm Animal Welfare Council, 2002), the Royal Society for the Prevention of Cruelty to Animals (Laurence, 2002), and the Dutch Society for the Protec- tion of Animals (van den Berg, 2002; Nederlandse Vereniging tot Bescherming van Dieren, 2004) have monitored, evaluated, and criticized the animal welfare situation during the 2001 foot and mouth epidemic.

The scale of the slaughter to be performed within a limited time-frame, combined with a control strategy which was not adequate to deal with the scale of the epidemic, led to animal welfare problems involving cases of improper handling, killing, stunning, and transport of animals. Handling, restraint and killing methods in the field are very different from those in slaughterhouses. Concern was expressed over the unsuitable conditions for on-farm slaughter and inappropriate killing methods. These problems were exacerbated by the fact that handling and slaughter were sometimes in the hands of unskilled personnel not accustomed to working in disease control/field situations, and because delays had taken place in the slaughter of infected animals. Movement restrictions due to a transport ban and a shortage in forage and bedding were reported to cause major animal welfare problems. Concern was expressed that uninfected animals had suffered severe welfare problems, or were killed unnecessarily for want of feed or land. Overcrowding caused grave physical problems in rapidly growing poultry and aggression and cannibalism in pigs. Transport sometimes took place over long distances and was a cause of further welfare problems.

\section{Ethical issues}

The last century has seen a major change in the mentality and attitude towards animals. Where people once regarded animals from a purely instrumental point of view, a shift has taken place towards a more protective and respectful attitude towards them. This has resulted in changing attitudes concerning the proper treatment of animals during their life and also in different views with respect to the killing of animals. Many considered the culling of healthy animals in the stamping-out of an epidemic as senseless, even though production animals are destined to be slaughtered for the food production anyway.

Noordhuizen-Stassen et al. (2003) performed a study into the societal and moral acceptability of the killing of kept animals. The views about the culling of so many (healthy) animals during the epidemics were taken as one example of the changing views concerning human-animal relationship.

A total of 1,939 respondents selected from the Dutch general public participated in the study, and in-depth interviews were performed with 43 experts. The majority $(84 \%)$ of the respondents were of the opinion that the culling of healthy animals is morally unacceptable when the control strategy is based exclusively on economic motives, which are governed by European trade policies 
serving the livestock industry, which can be fairly described as large-scale and focused on the export market. The prevailing view was that the control strategy values economic interests over the lives of living creatures. It was not, however, considered unacceptable to kill animals for food production. The moral basis of this view was a respect for life taking into account the natural course of life of the animal. In this view, the killing of a healthy animal for the production of food is considered acceptable because it is the natural life cycle of a production animal; but the culling and destruction of healthy animals as a control measure during an epidemic for economic reasons is considered unacceptable because the "natural function" of the animal would not yet have been fulfilled.

These findings were corroborated by Stafleu et al. (2004), who described the opinion of three groups of four to seven Dutch pig farmers about their relationship to their animals. These farmers felt that the farmer and the animal each have a role to fulfill in the world as providers of high quality food. The animal is therefore functionally determined to live the life of a production animal. Culling healthy animals during an epidemic is considered senseless, since the animals had not been able to fulfill their task as production animals.

\section{European survey}

In 2004 a survey was conducted in the member states of the European Union to describe and analyze the economic, epidemiological, veterinary, and social-ethical consequences of the control strategy applied during recent epidemics of foot and mouth disease, avian influenza, and classical swine fever in the European Union (van Asseldonk et al., 2005). The questions of the socioethical survey addressed the above-mentioned issues of concern and in this article the results are presented.

The aim of this socio-ethical survey is to give more insight into the respective views held in the different member states of the European Union on future prevention and control strategies with respect to the sociopsychological and the ethical consequences to the people and animals involved. The survey thus aims to contribute to the discussion about alternative future strategies that society may come to support.

It was analyzed whether there is consensus on future strategies among the different member states in the European Union or whether different views exist. It was hypothesized that member states with a recent history of major animal disease epidemics would have developed certain views about the strategy applied therein and strategies for the future, especially with respect to the social, ethical, and animal welfare issues. Under this hypothesis, member states with no recent history of epidemics might hold different views, or might not have a sense of urgency to participate in the discussion. Furthermore, it was hypothesized that member states in different regions in the European Union might, due to their different geographical, economic, cultural, social, and religious backgrounds, hold different views. It was also considered whether views on the culling of animals and on the socio-psychological consequences, reflect different priorities in different regions in the European Union.

\section{Methodology}

For this survey a total number of 639 stakeholders were approached. To ensure that the choice of stakeholders was a representative selection of stakeholders present in the European Union as a whole and per member state, thus reflecting the ideas of a broad range of people and views, each stakeholder should be a member of one of the following organizations: the Groupe Permanent "Questions Veterinaires"; 2 or a national representative of a European organization whose mission statement includes issues concerning epidemic animal diseases and their economic, social or ethical consequences; or a national organization directly linked to other relevant organizations or departments.

\section{Clustering member states}

The European Union does not categorize its member states by region in a manner relevant and applicable to this survey. Such categorization could be based on various criteria, for instance geographical, agricultural, or economic differences. In this survey the member states were regionalized into a northern, southern, and eastern region, based on their presumed geographical and cultural differences. The northern region included Austria, Belgium, Denmark, Finland, Germany, Ireland, Luxemburg, the Netherlands, Sweden, and the United Kingdom. The southern region included Cyprus, France, Greece, Italy, Portugal, Malta, and Spain. The eastern region include the Czech Republic, Estonia, Hungary, Latvia, Lithuania, Poland, the Slovak Republic, and Slovenia

The member states were clustered into either a positive- or a negative-outbreak cluster, based on data from the OIE Handistatus II. Only member states which experienced one or more major epidemics (in terms of number of animals and/or a history of more than one epidemic) between 1996 and 2003 were clustered in a "positive-outbreak cluster." Incidental small outbreaks, which involve only a limited number of farmers and animals, have no major social impact on the community. Therefore member states with incidental outbreaks or no outbreaks at all were clustered in a "negative-outbreak cluster." The positive-outbreak cluster included Belgium, 
Germany, Ireland, Luxemburg, the Netherlands, United Kingdom, France, Greece, Italy, Spain, Czech Republic, and Slovak Republic. The negative-outbreak cluster included Austria, Denmark, Finland, Sweden, Cyprus, Portugal, Estonia, Hungary, Latvia, Lithuania, Poland, Slovenia, and Malta.

Moreover, the United Kingdom, the Netherlands, and Italy were clustered into a separate "high-incidence cluster." This was based on the fact that these member states had each experienced recent outbreaks of (multiple) major epidemics with a high impact on society. It was postulated that this experience might distinguish these member states from the other member states in the European Union. Thus three country clusters were made: a negative-outbreak cluster, a positive-outbreak cluster, and a high-incidence cluster.

\section{Clustering stakeholders}

The stakeholders were clustered as follows:

- Representatives of the authorities. In this case the respondents were the Chief Veterinary Officers (CVOs) $;^{3}$

- Livestock industries and unions;

- Sectors directly linked to the livestock industry, such as the food-processing industry, slaughterhouses, and the transport sector (SL);

- Sectors not directly linked to the livestock industry, such as the tourism sector and retailers $(\mathrm{SnL})$;

- Veterinary organizations and scientific veterinary institutes;

- Non-governmental organizations (NGOs), such as organizations for nature conservation, zoos, the environment, animal welfare and protection, breeders and keepers of rare breeds or backyard animals, consumer organizations, organizations dedicated to social issues, human health, or religion;

- Scientific academies or institutes in the field of agricultural or animal science, social studies, animal welfare, philosophy, ethics, food safety, and other relevant fields.

\section{Questionnaire}

A total of 639 questionnaires, translated into four languages, were sent by mail or e-mail. The survey consisted of closed questions, i.e. the respondent could only choose among a limited number of answers (indicators). This may have excluded certain issues of importance, but in such a large-scale survey this is unavoidable for a useful comparative analysis. The questions focused on (1) the position of the stakeholders in the decision-making process; (2) their views about the current control strategy applied during an epidemic; and (3) their priorities for future policy.
Respondents were invited to score priority indicators, thus identifying the stakeholders' priorities in the discussion about current and future strategies. It is likely that different stakeholders will have different priorities and missions, which will lead them to having different ideas about the strategy to be chosen. This may create a situation of conflicting interests between stakeholders. Economic motives may prevail in the views of some; animal or human welfare motives may be prominent in the views of others. Each stakeholder will present arguments which are considered relevant from one particular point of view. These views will be reflected in the choice of indicators.

The total of scores was used to create a priority list. In the public debate, this priority list can be used as a starting point for a further discussion about future alternative strategies.

Stakeholders with a direct economic interest in the applied control strategy, such as farmers, agricultural organizations, and food-processors, are likely to have a prominent position in the decision-making process. Local authorities and veterinarians, who are responsible for communicating and executing the strategy, are also indispensable partners in the discussion. But the impacts of recent epidemics have made clear that economic and veterinary arguments by themselves afford insufficient grounds to justify the choice of a strategy. Sociological, psychological, and ethical issues have taken an increasingly prominent position in the public debate. A strategy based on non-vaccination, movement restrictions, and massive culling of healthy animals that is insufficient in its attention to communication, animal welfare, and social consequences will meet with less support from the farming community and others directly involved as well as from the general public. A national government can recognize and accommodate these views by including representatives of organizations such as animal welfare organizations, breeders and keepers of backyard animals, human health organizations, zoos, nature conservation, the tourism sector, and consumer organizations in the discussion. Therefore, it is argued here that those issues that have received a prominent position in the national public debate, and as such are acknowledged by the national authority, are reflected in the spectrum of stakeholders involved in the decision-making process.

\section{Data analysis}

Comparative rating scales were used for deriving relative judgments by asking the respondent to divide 100 points between the indicators according to his or her assessment of their importance. These comparative rating scales required the respondents to make judgments on each indicator with direct reference to judgments on the other indicators being evaluated (van Asseldonk et al., 2005). 
The data were analyzed by member state and by stakeholder cluster, and presented in percentages. The number of questionnaires received per member state and per stakeholder cluster as well as the number of stakeholders per cluster was unevenly distributed. Therefore, the results are presented at the regional level and not at the stakeholder level.

\section{Results}

One or more responses were received from 24 member states and from 6 stakeholder clusters. No representatives from Malta or from the $\mathrm{SnL}$ cluster responded to the questionnaire. A total number of 86 questionnaires were received, which is a response rate of $13 \%$. The highest response rate came from Northern Europe $(19 \%)$ and more specifically the Netherlands $(47 \%)$. In the stakeholder cluster the government and the veterinary organizations had the highest response rate: $76 \%$ and $25 \%$, respectively. Because many member states have not experienced recent outbreaks and involvement of a broad spectrum of stakeholders in these member states in a discussion about alternative strategies presumably has not been an issue, the response rate from those member states was (as expected) low. Northern Europe was represented with 59 respondents from 11 member states, Southern Europe with 16 respondents from 5 member states and Eastern Europe with 12 respondents from 8 member states.

Most respondents were involved in the decisionmaking process $(74 \%)$, especially the CVOs $(100 \%)$ and the veterinary organizations $(92 \%)$. Fourteen percent of the respondents were not involved, and $12 \%$ did not indicate their involvement. The next-highest levels of stakeholder involvement were by the livestock industry $(69 \%)$, NGOs $(63 \%)$, the SL $(58 \%)$, and scientific organizations $(57 \%)$.

The respondents were asked which stakeholder groups in their country are the most important actors in the decision-making process of a control strategy. All stakeholders were unanimous in their opinion that the government is the most important actor, followed by the farmers unions and the veterinarians. This outcome was to be expected, since it is ultimately the national and European policy-makers who govern the regulations and make the decisions about the control strategy to be applied. It was interesting to see which stakeholders were considered to have the least influence of all, i.e., the keepers of backyard animals and the SnL sector. The protest of the former group against the culling of healthy backyard animals has only been prominent in the
Netherlands and not so much in other member states. As noted above, no representatives from the SnL category responded to the questionnaire.

The efficiency of a control strategy to successfully eradicate a disease was seen by most as the most important issue in recent epidemics, followed by the social and financial consequences for the people involved (Table 1). Animal health and welfare scored third place. In the Netherlands, animal welfare scored second place and was considered a more important issue than efficiency. Animal health and welfare were considered less important issues in the United Kingdom and Italy. The veterinary organizations and the NGOs gave a higher priority to animal health and welfare as compared to the other stakeholders.

All respondents chose epidemiological criteria as the most important consideration in the choice of a control strategy, followed by economic criteria. The exception was the NGOs who rated socio-ethical criteria in second place. This result does not necessarily reflect the situation the respondents would prefer, but may instead reflect the present situation as viewed by the stakeholders. Not all respondents are involved in the decision-making process, and they may feel that socio-ethical criteria should, but in practice are not given a high enough priority.

The priority order of important issues for future strategies was largely similar in the positive- and the negative-outbreak clusters, but different in the different regions and in the high-incidence cluster (Table 2).

In the positive- and negative-outbreak clusters the order was (1) preventive measures and (2) social, psychological, and financial consequences. Respondents from Northern and Southern Europe considered preventive measures the most important issue. In Northern Europe communication was deemed almost as important and rated second place. Respondents from Eastern Europe chose social, psychological, and financial consequences as the number one priority issue and preventive measures second. Overall, animal welfare and related ethical issues scored third or fourth place. The Netherlands considered animal welfare to be the highest priority issue and socio-psychological and financial issues and preventive measures shared second place. In the United Kingdom the socio-psychological and financial issues were chosen as the first priority issue and communication rated second place. In Italy preventive measures and communication were considered first and second, respectively. In the stakeholder cluster preventive measures scored the highest. Animal welfare scored relatively low with the stakeholders in or related to the livestock industry. The NGOs considered a communication procedure to be the first priority and animal welfare scored second place. 
Table 1. Relevant issues in the control strategy applied by percentage.

\begin{tabular}{|c|c|c|c|c|c|c|c|c|}
\hline & Efficiency & $\begin{array}{l}\text { Socio- } \\
\text { economic }\end{array}$ & $\begin{array}{l}\text { Macro- } \\
\text { economic }\end{array}$ & $\begin{array}{l}\text { Commercial } \\
\text { interest }\end{array}$ & $\begin{array}{l}\text { Animal } \\
\text { health }\end{array}$ & $\begin{array}{l}\text { Animal } \\
\text { welfare }\end{array}$ & Tourism & $\begin{array}{l}\text { Natural } \\
\text { life-cycle } \\
\text { production } \\
\text { animal }\end{array}$ \\
\hline Northern Europe & 23 & 15 & 9 & 8 & 9 & 9 & 6 & 5 \\
\hline Southern Europe & 25 & 14 & 8 & 11 & 9 & 11 & 3 & 5 \\
\hline Eastern Europe & 18 & 15 & 9 & 10 & 4 & 13 & 6 & 5 \\
\hline $\begin{array}{l}\text { Positive-outbreak } \\
\text { clusters }\end{array}$ & 23 & 14 & 9 & 9 & 9 & 10 & 4 & 4 \\
\hline $\begin{array}{l}\text { Negative-outbreak } \\
\text { clusters }\end{array}$ & 20 & 15 & 7 & 9 & 6 & 11 & 9 & 7 \\
\hline $\begin{array}{l}\text { The Netherlands } \\
\text { high-incidence }\end{array}$ & 12 & 14 & 14 & 9 & 12 & 13 & 2 & 7 \\
\hline $\begin{array}{l}\text { United Kingdom } \\
\text { high-incidence }\end{array}$ & 26 & 16 & 6 & 9 & 9 & 8 & 9 & 5 \\
\hline Italy high-incidence & 24 & 19 & 6 & 18 & 9 & 7 & 3 & 3 \\
\hline Total high-incidence & 21 & 16 & 9 & 12 & 10 & 9 & 5 & 5 \\
\hline Government & 21 & 16 & 14 & 15 & 8 & 13 & 7 & 7 \\
\hline Livestock industry & 26 & 35 & 4 & 5 & 6 & 5 & 11 & 10 \\
\hline SL industry & 32 & 11 & 19 & 17 & 6 & 8 & 4 & 4 \\
\hline $\begin{array}{l}\text { Veterinary } \\
\text { organizations }\end{array}$ & 31 & 17 & 4 & 5 & 12 & 20 & 6 & 5 \\
\hline NGOs & 31 & 9 & 5 & 8 & 15 & 18 & 7 & 6 \\
\hline $\begin{array}{l}\text { Scientific } \\
\text { organizations }\end{array}$ & 18 & 34 & 8 & 12 & 10 & 7 & 5 & 5 \\
\hline Total stakeholders & 27 & 20 & 9 & 10 & 10 & 12 & 7 & 6 \\
\hline
\end{tabular}

Highest values are in bold; SL = Sectors not directly linked to the livestock industry; NGOs = non-governmental organizations.

Table 2. Priority issues for future strategies by percentage.

\begin{tabular}{|c|c|c|c|c|c|c|}
\hline & Communication & $\begin{array}{l}\text { Socio-psychological } \\
\text { and financial } \\
\text { consequences }\end{array}$ & $\begin{array}{l}\text { Animal } \\
\text { welfare and } \\
\text { related } \\
\text { ethical issues }\end{array}$ & $\begin{array}{l}\text { Preventive } \\
\text { measures }\end{array}$ & $\begin{array}{l}\text { Reputation } \\
\text { and position } \\
\text { agricultural } \\
\text { sector }\end{array}$ & Other issues \\
\hline Northern Europe & 24 & 21 & 17 & 25 & 8 & 5 \\
\hline Southern Europe & 21 & 23 & 12 & 29 & 8 & 6 \\
\hline Eastern Europe & 14 & 34 & 18 & 26 & 8 & 0 \\
\hline $\begin{array}{l}\text { Positive-outbreak } \\
\text { clusters }\end{array}$ & 21 & 23 & 18 & 25 & 8 & 5 \\
\hline $\begin{array}{l}\text { Negative-outbreak } \\
\text { clusters }\end{array}$ & 24 & 24 & 11 & 29 & 8 & 4 \\
\hline $\begin{array}{l}\text { The Netherlands } \\
\text { high-incidence }\end{array}$ & 14 & 23 & 30 & 23 & 9 & 0 \\
\hline $\begin{array}{l}\text { United Kingdom } \\
\text { high-incidence }\end{array}$ & 20 & 28 & 16 & 18 & 17 & 3 \\
\hline Italy high-incidence & 23 & 18 & 14 & 38 & 7 & 0 \\
\hline Total high-incidence & 19 & 23 & 20 & 26 & 11 & 1 \\
\hline Livestock industry & 22 & 29 & 9 & 27 & 11 & 1 \\
\hline SL industry & 18 & 25 & 9 & 29 & 8 & 12 \\
\hline Veterinary organizations & 23 & 18 & 20 & 29 & 9 & 2 \\
\hline NGOs & 27 & 22 & 23 & 21 & 4 & 3 \\
\hline Scientific organizations & 15 & 27 & 21 & 27 & 10 & 0 \\
\hline Total stakeholders & 21 & 24 & 16 & 27 & 8 & 4 \\
\hline
\end{tabular}

Highest values are in bold; SL = Sectors not directly linked to the livestock industry; NGOs = non-governmental organizations. 


\section{Discussion}

In this discussion, the results from this survey are compared to other studies and to recommendations made by expert committees.

Studies performed in the Netherlands and the United Kingdom have focused on the sociological and psychological consequences of animal epidemics and on the ethical issues of culling healthy animals. Expert committees in the United Kingdom (Anderson, 2002; The Royal Society, 2002) and in the Netherlands (Raad voor het Landelijk Gebied and Raad voor Dieraangelegenheden, 2003, 2004) have issued advice on future policy, including risk assessment and preventive measures, vaccination, contingency planning, communication, and animal welfare. Animal welfare organizations have advised specifically on animal welfare issues (Farm Animal Welfare Council, 2002; Laurence, 2002; van den Berg, 2002).

\section{Preventive measures}

Preventive measures serve to reduce the risk of transmission of the virus and include hygiene measures and measures to regulate human-animal and animal-animal contact. Preventive measures are of course all-encompassing in tackling all the issues under discussion, because the prevention of an animal disease epidemic will prevent human trauma and the culling of animals at the same time. Therefore, the respondents' choice for preventive measures as the most important priority issue reflects their conviction that it is better to reduce the risk of an outbreak than to eradicate a disease, and is in line with the recommendations made by the expert committees.

The expert committees considered it imperative to provide farmers and keepers of backyard animals with relevant information about prevention, spread, and hygiene. A zero-risk situation was not considered feasible, but preventive measures taken within the farming business, such as better hygiene and hygiene protocols, attention to contact structure between farms (animalanimal and animal-human), a strong reduction of animal transport, and improved diagnostics should result in reducing the risk factor. The committees argued that there should be a differentiation in control and preventive measures per animal species, business type, region, and disease. In the long run, compartmentalization of agricultural regions of cattle-farms is required. An "Early Warning System" as formulated by the Royal Society (2002), should monitor international animal transport to facilitate timely measures.

Vaccination as a preventive measure is also presented as a valid tool to prevent diseases from occurring or spreading. In recent public discussions, many questioned the European non-vaccination policy. It was felt that international trade and market priorities drove the World Trade Organization decision to maintain an infection-free status without preventive vaccination in the European Union member states. Preventive vaccination is more expensive as compared to pre-emptive culling and stamping-out of an emerging disease. Veterinary and socio-psychological motives which favor preventive vaccination and other consequences of this policy, such as the consequences for tourism, zoo animals, wildlife, rare breeds, and the reputation of the agricultural sector, were not taken into consideration (Koninklijke Nederlandse Akademie van Wetenschappen, 2002). Furthermore, inclusion on the OIE list of "foot and mouth disease-free countries without preventive vaccination" gives countries the right to ban the import of meat products from countries where vaccination is applied or where foot and mouth disease has emerged, thus protecting a listed country's own market.

The expert committees have recommended further possible use of emergency vaccination-to-live during an epidemic, since vaccination contributes to a reduction in the number of animals culled. In the Netherlands the control strategy had included emergency vaccination of all susceptible animals to stop the disease from spreading, but these animals were subsequently culled. Furthermore, vaccination-to-live should include noninfected animals, backyard and recreational animals, zoo animals, and rare breed ruminants.

Having emergency vaccination-to-live as part of a control strategy necessarily implies that meat and meat products from vaccinated animals will enter the food chain normally. As a consequence, the trading of products of vaccinated animals on the international market should receive extra attention, including consumer information. During the foot and mouth disease crisis in the United Kingdom, the Nestle Company expressed serious reservations about accepting milk from vaccinated cows because it presumed and feared a consumer reaction. This was referred to as the "Nestle factor." It was unanimously agreed that there is a complete absence of any danger associated with vaccinated products, and it was considered important to encourage retailers to facilitate the marketing of vaccinated products.

Vaccination is also supported by animal welfare organizations. According to the Farm Animal Welfare Council (2002) an effective national policy of compulsory vaccination is an option, provided it has been granted European Union approval and provided the public is reassured that products from vaccinated animals present no food safety issue. During an epidemic, ring fencing by vaccination, leading to fewer animals being culled, has significant welfare benefits. The Dutch Society for the Protection of Animals (van den Berg, 2002) favors a Europe-wide policy for preventive vaccination, including preventive vaccination of rare breeds, 
zoo animals and backyard animals, and emergency vaccination-to-live.

Animal epidemics and the culling of animals are not restricted to farm animals; they afflict backyard animals and animals in nature reserves and zoos as well. In the Netherlands, the discussion whether or not to vaccinate zoo animals, endangered species, (semi) wildlife and rare animals was just as intense as the public outrage at the destruction of backyard animals. Rare breed ruminants often inhabit nature reserves for the purposes of cropping the fields, for biodiversity, and the enjoyment of experiencing animals in a natural environment. Zoos house many rare and valuable species and are involved in international breeding programs for endangered species. Schaftenaar (2002), in a paper for the special OIE series on foot and mouth disease issues, stated that the international community recognizes the importance of these breeding programs. In his paper Schaftenaar recommends that the zoo community should propose an international research program to study the efficacy of vaccines and the application of diagnostic tests in non-domestic animals kept in zoos; zoos could then apply to the OIE for recognition of their participation in such a research program as zones free of foot and mouth disease, where vaccination is applied.

At the time of this writing in 2006, a pilot study on vaccinating backyard animals is taking place in the Netherlands. The results of this pilot study will be presented to the other member states.

\section{Communication}

In their advice, the Dutch Councils acknowledged that during the recent crises, lack of communication led to frustration among those involved. There is a need to give more attention to improved communication between central and local authorities. It was further emphasized that the development and execution of future strategies are a shared responsibility and that all stakeholders should thus participate in the discussion about updating contingency plans. In this discussion, the moral outrage at the massive culling of healthy animals requires special attention, since this involves society as a whole. Keepers of backyard and zoo animals and nature conservation organizations demand more attention to their specific situation.

Furthermore, it was recommended that authorities should be better prepared, specifically by organizing a local crisis team consisting of people with knowledge of the situation who would give more attention to social aid during and after a crisis.

\section{Reputation and position of the agricultural sector}

Stafleu et al. (2004) have described the changing reputation of the farming community and society's critical attitude towards the agricultural business, partly as a result of recent crises. Farmers are criticized because of the relationship assumed to exist between current farming practices (large-scale factory farming) and the disastrous effects of recent epidemics. It is thought that farmers are guided mainly by economic motives, and less so by a concern for animal welfare, food safety, and the environment.

The pig farmers (three groups of four to seven people) interviewed for this study claimed that their priorities and motivation for farming include respect for animals, business continuity, and living with the seasons. Farmers value free enterprise, and farming is often a family business. They appreciate working with the living nature and animals. Respect for animals, in their view, usually finds expression in matters of health and welfare. They respect the functions prescribed to the production animal and the farmer; i.e., the farmer and the animal have a shared role to fulfill in the world as providers of high quality food. This is considered more a calling than a profession; it is a way of life and the very essence of being a farmer. In this respect the culling of a healthy animal (even in a crisis) is considered a sin, because the natural function of the production animal will not be fulfilled.

Another Dutch study (van Haaften and Kersten, 2002) identified two categories of dairy farmers. The farmers in the first category were described as motivated by economic motives, and they considered animals as a production factor. The farmers in the second category were emotionally attached to their animals, acknowledged the intrinsic value (a value in their own right) of animals, and granted animals a central position in the farming business, even considering them as members of the family. These different points of view were reflected in the preferred choice of control strategy to be applied. The first category regretted the culling of animals but emphasized the importance of a strong position on the international export market. The second category was deeply angered by the culling of healthy animals, especially since there was a vaccine at hand. Farmers whose philosophy of life includes respect for the natural course of life were especially outraged. Under the current policy, this category of farmers felt they were forced to run their business in a non-animal friendly way and could not understand the non-vaccination policy in order to protect export interests.

The reputation and position of the agricultural sector was considered the least important issue in the European survey and usually came up last in the priority listing. Expert committees did not address the issue explicitly, but implicitly a future policy should rely on a better understanding and a shared responsibility between all stakeholders. Therefore, a control strategy which is acceptable in the public domain will likely improve the reputation of the livestock industry. 


\section{Conclusion}

The results of this survey show that the recommendations made by expert committees and animal welfare organizations are in line with the results of this study, especially with respect to preventive measures and social, animal welfare, and ethical issues. Therefore, even though the response rate was low, some conclusions can be drawn.

The hypothesis that the positive-outbreak cluster and the negative-outbreak cluster might hold different views concerning animal welfare and socio-psychological issues could not be substantiated from the results of the priority listing. The results furthermore showed that the priority orders expressed in the three member states of the high-incidence cluster (the Netherlands, the United Kingdom, and Italy) differed from one another.

The hypothesis that stakeholders from different regions of the European Union might hold different views concerning the priority issues was substantiated as each of the three regions responded with a different priority order. It is interesting to note that socio-psychological and financial issues rated highest with respondents in Eastern Europe, even though no member state in this region has recently had a major epidemic. We recognize that this survey is just a first step and the results may have been affected by the limited number of stakeholders from this region who had responded, and because the representation of stakeholders was not evenly distributed in and between the member states. Therefore, we can only speculate to explain the results.

These differences in views may be attributed to variations in agricultural history and structure of the rural areas of the individual regions. In Northern Europe for example and in the Netherlands in particular, the agricultural sector has shifted towards large-scale agribusinesses depending mainly on the export of animals and animal products. Consequently, animal epidemics affect the livestock sector as whole. Opting for preventive measures requires a (financial) commitment of all parties involved in the livestock sector because the effectiveness of preventive measures is dependent on the cooperation of all. The livestock industry in Eastern European countries is not homogenous. The dual farm structure found there is no doubt one of the characteristics of agriculture which impacts the views held in these member states. For example, there are many small farms which are often part-time in nature; but there are also very large enterprises. The emphasis in these countries may be less on the export of products than on individual efforts to improve the efficiency of one's business in terms of modernization and production. It can be plausibly concluded that different priorities on control strategies might be attributed to different levels of perception: export-oriented countries may think in terms of the benefit to the livestock sector as a whole, while Eastern
European countries may consider the consequences for the individual farmer first. The outcome may mirror farmers' individual interests versus sector interests. This duality of interests was observed at the national level in the study of van Haaften and Kersten (2002), who described a clash of interests between farmers who valued a strong international trade position over the lives of their animals against farmers who had failed to see the justification of a non-vaccination policy and who had suffered deeply over the loss of their animals.

\section{Recommendations}

The survey has given a first impression of the spectrum of views held in the member states of the European Union on the subject of future control policies. We recommend further research not only at the European, but at the national level as well, for several reasons. First, relevant stakeholders are more easily identified and approached at the national level. This should stimulate their involvement in the survey, thereby increasing the response rate and in turn resulting in a more representative number of respondents from all stakeholder categories. Second, a stakeholder study at the national level may very well uncover issues of importance not addressed in this study, in which the stakeholders' possible responses were limited to the indicators presented them. While these were comprehensive, other relevant issues and indicators are certainly possible. Lastly, a series of comparative national surveys would potentially offer greater understanding of the regional differences observed herein.

The diversity in the spectrum of views observed and described herein may be the result of the various respondents' individual experiences with outbreaks, of a stakeholder's position in the public debate, and of social and cultural differences between the member states. Such social and cultural differences may be reflected in differing perspectives on what constitutes morally acceptable treatment of animals. The relationship between man and animal has in recent years evolved from a purely functional relationship in which the animal is valued mostly for its instrumental utility to humans, towards one in which respect for the value of the animal as a being in its own right plays a significant role. The debate about animal welfare and respect for life varies in prominence from one member state to another and may also vary with respect to animal species (e.g., cloven-hoofed animals versus poultry). While beyond the scope of this study, it would be interesting and useful to examine how views on our moral responsibility towards animals differ in various member states and whether differences should be understood in terms of differences in culture, rural structure, or otherwise. 
Actions taken to control recent epidemics consistently indicated a balancing between the interests of the various stakeholders; but in the Netherlands, acknowledgement that keepers of backyard animals, who keep animals for non-commercial purposes, and professional livestock farmers have different interests came only after the epidemics had been contained. Over the last few decades, the scale of livestock farming in the Netherlands has grown considerably, even though the number of farms and farmers has decreased. At the same time, ever more people are keeping backyard animals for company, for breeding, or for recreational purposes. These people usually have a strong emotional bond with their animals and fail to see the justification for culling healthy animals for economic reasons. This has led to major traumas and to strong resistance to the culling of healthy backyard animals within this group. In order to avoid or at least mitigate this, any successful control strategy need take into account the non-economic interests of this group. Towards this end, a national-level survey could identify to what extent keepers of backyard animals in the different member states can and should be seen as a separate group with their own interests. Such a survey would require a sound definition of this potential new stakeholder group, in order to distinguish its members from professional farmers.

The balancing of interests applied in controlling epidemics has involved not only the interests of the different stakeholders, but also the interests of humans (economic, financial, and social) on the one hand and animals (welfare issues, respect for life) on the other. Recent outbreaks of avian influenza H5N1 in 2005 and 2006 posed a novel health hazard to humans. In a future outbreak of avian influenza $\mathrm{H} 5 \mathrm{~N} 1$, a potential human health risk may lead to a re-balancing of interests. An additional survey with a focus on the outbreaks of avian influenza of type H5N1 in Europe in 2005 and 2006 may clarify how a potential human health risk is appraised in the balancing of human versus animal interests.

Vaccination as a means of preventing or controlling an animal disease - whether with or without an attendant human health risk - has been extensively discussed in recent conferences, as well as by expert committees. Both preventive vaccination and emergency vaccinationto-live are considered valuable and sensible choices for addressing these concerns in the future, as they offer the advantages of avoiding further social and psychological trauma to those involved and the culling of healthy animals.

\section{Acknowledgments}

We would like to thank Leo den Hartog, Johan Statius Muller, and Stellajane Holmes for their valuable advice and assistance.

\section{Notes}

1. Data about the number of animals infected and culled during animal disease epidemics and data about countries with outbreaks of animal diseases were obtained from the World Organisation for Animal Health (Office International de Epizooties) at http://www.oie.int: Handistatus II.

2. National representatives of the European organizations organized in the Groupe Permanente "Questions Veterinaires" are: Committee of Agricultural Organizations in the EU (COPA), General Committee for Agricultural Co-operation in the EU (COGECA), European Liaison Committee for the Agri-food Trade (CELCAA), Confederation of Family Organizations in the European Community (COFACE), Confederation of the Food and Drink Industries of the EU (CIAA), Eurocommerce, European Community of Consumers Co-operatives (EUROCOOP), European Consumers Organization (BEUC), European Federation of Trade Unions in the Food, Agriculture and Tourism Sectors and Allied Branches (EFFAT), Federation of Veterinarians of Europe (FVE), Syndicat Européen des Travailleurs de l'alimentation de l'hôtellerie et des Branches Connexes (SETA-UITA) dans l'UITA (observer).

3. CVOs are the chief veterinary officers who are responsible for the veterinary policy advice to the minister, formal admittance of veterinary medical products, veterinary disciplinary law, animal welfare and crisis management.

\section{References}

Anderson I. (2002). Foot and Mouth Disease: Lessons to be Learned Inquiry Report. HC888 July 22, 2002. London, United Kingdom: The Stationary Office.

Cumbria Foot and Mouth Disease Inquiry Panel (2002) Cumbria Foot and Mouth Disease Inquiry Report. Retrieved from http://www.cumbria.gov.uk on June 1, 2004.

Farm Animal Welfare Council (2002). Foot and Mouth Disease 2001 and Animal Welfare: Lessons for the Future. London, United Kingdom: Farm Animal Welfare Council.

Huirne, R. B. M., M. Mourits, F. Tomassen, J. J. de Vlieger, and T. A. Vogelzang (2002). MKZ Verleden, Heden en Toekomst, over de Preventie en Bestrijding van MKZ. The Hague, the Netherlands: Landbouw Economisch Instituut.

Institute for Health Research (2002). Evidence Submitted to Cumbria Foot and Mouth Disease Inquiry. Lancaster, United Kingdom: Lancaser University. 
Koninklijke Nederlandse Akademie van Wetenschappen (2002). Bestrijding van Mond - en Klauwzeer, 'Stamping Out' of Gebruik Maken van Wetenschappelijk Onderzoek. Amsterdam, The Netherlands: Royal Netherlands Academy for Arts and Sciences.

Laurence, C. J. (2002). "Animal welfare consequences in England and Wales of the 2001 epidemic of foot and mouth disease." Scientific and Technical Review of the Office International de Epizooties 21(3): 863-868.

Nederlandse Vereniging tot Bescherming van Dieren (2004). Reactie van de Dierenbescherming op de Evaluatie van de Vogelpestcrisis 2003 n.a.v. het Rapport van het Bureau Berenschot en de Reactie van het Kabinet. The Hague, The Netherlands: Dutch Society for the Protection of Animals.

Noordhuizen-Stassen, E. N., L. J. E. Rutgers, and J. M. Swabe (2003). Het Doden van Gehouden Dieren. Utrecht, The Netherlands: Utrecht University.

Raad voor het Landelijk Gebied and Raad voor Dieraangelegenheden (2003). Dierziektebeleid met Draagvlak, Advies over de Bestrijding van Zeer Besmettelijke Dierziekten, Deel 1 Advies. Report RLG 03/8 RDA 2003/08. The Hague, The Netherlands: The Council for the Rural Area and The Council for Animal Affairs.

Raad voor het Landelijk Gebied and Raad voor Dieraangelegenheden (2004). Dierziektebeleid met Draagvlak, Advies over de Bestrijding van Zeer Besmettelijke Dierziekten, Deel 2 Onderbouwing van het Advies. Report RLG 03/8 RDA 2004/01. The Hague, The Netherlands: The Council for the Rural Area and The Council for Animal Affairs.

Royal Society (2002). Infectious Diseases in Livestock, Scientific Questions Relating to The Transmission, Prevention and Control of Epidemic Outbreaks of Infectious Disease in Livestock in Great Britain. London, United Kingdom: The Royal Society.
Schaftenaar, W (2002). "Use of vaccination against foot and mouth disease in zoo animals, endangered species and exceptionally valuable animals." Scientific and Technical Review of the Office International de Epizooties 21(3): 613-623.

Stafleu, F. R., C. C. Lauwere, K. H. de Greef, P. Sollie, and S. Dudink (2004). Boerenethiek. Eigen Waarden als Basis voor een 'Nieuwe' Ethiek. Een Inventarisatie. Utrecht, The Netherlands: Ethics Institute, Utrecht University.

van Asseldonk, M., R. M. K. de Jong Vlieger, and M. Huirne (eds.) (2005). Prevention and Control of Foot and Mouth Disease, Classical Swine Fever and Avian Influenza in The European Union: An Integrated Analysis of Epidemiological, Economic and Social-Ethical Aspects. Wageningen and Utrecht. The Netherlands: Wageningen University and Research Centre, Utrecht University, Consortium for Veterinary Epidemiology and Economics.

van den Berg, B. (2002). Evaluatie van het Welzijn van Dieren tijdens de Mond - en Klauwzeercrisis in Nederland in 2001. The Hague, The Netherlands: Dutch Society for the Protection of Animals.

van Haaften, E. H., and P. H. Kersten (2002). Veerkracht. Report no. 539. Wageningen, The Netherlands: Alterra.

van Velzen, K. and I. Dekker (2003). Niet Ruimen, maar Prikken! Hoe Nederland Opnieuw Massaal Gezonde Dieren Liet Afmaken. The Hague, The Netherlands: TweedeKamerfractie SP.

Address for correspondence: Nina E. Cohen, Wageningen Institute for Animal Sciences, Animal Production Systems Group, Animals and Society, Wageningen University, P.O. Box 338 Wageningen, $6700 \mathrm{AH}$, The Netherlands

Phone: +31-317-483651; Fax: +31-317-485550;

E-mail: nina.cohen@wur.nl 